\title{
DESIGN CONTROL OF SURFACE MARINE VEHICLE USING DISTURBANCE COMPENSATING MODEL PREDICTIVE CONTROL (DC-MPC)
}

\author{
Sari Cahyaningtias ${ }^{1}$, Tahiyatul Asfihani ${ }^{2}$, Subchan Subchan ${ }^{3 *}$ \\ ${ }^{1}$ School of Mathematical and Statistical Sciences, Arizona State University, \\ Tempe, Arizona, 85287, United State of America \\ 2,3 Department of Mathematics, Faculty of Science and Technology, \\ Institut Teknologi Sepuluh Nopember, Kampus ITS Sukolilo, Surabaya, 61111, Indonesia \\ Corresponding author e-mail: ${ }^{3 *}$ subchan@matematika.its.ac.id
}

\begin{abstract}
This research studied ship motion control by considering four degrees of freedom (DoF): yaw, roll, sway, and surge in which comprehensive mathematical modeling forming a nonlinear differential equation. Furthermore, this research also investigated solutions for fundamental yet challenging steering problems of ship maneuvering using advanced control method: Disturbance Compensating Model Predictive Control (DC-MPC) method, which based on Model Predictive Control (MPC). The DC-MPC allows optimizing a compensated control then consider sea waves as the environmental disturbances. Those sea waves influence the control and also becomes one of the constraints for the system. The simulation compared the varying condition of Horizon Prediction (Np) and another method showing that the DC-MPC can manage well the given disturbances while maneuvering in certain Horizon Prediction. The results revealed that the ship is stable and follows the desired trajectory.
\end{abstract}

Keywords: DC-MPC, horizon prediction, optimal control, rudder angle, ship maneuver.

How to cite this article:

S. Cahyaningtias, T. Asfihani, Subchan, "DESIGN CONTROL OF SURFACE MARINE VEHICLE USING DISTURBANCE COMPENSATING MODEL PREDICTIVE CONTROL (DC-MPC)”, BAREKENG: J. Il. Mat. \& Ter., vol. 15, no. 1, pp. 167-178, Mar. 2021.

\section{(c) () (?)}

This work is licensed under a Creative Commons Attribution-ShareAlike 4.0 International License.

Copyright (C) 2021 Sari Cahyaningtias, Tahiyatul Asfihani, Subchan Subchan 


\section{INTRODUCTION}

The surface marine vehicle is one of the best choices for either industrial transportation or military purposes since it is designed to operate with adequate reliability and economy [1]. Indonesia is an archipelago country, which is two of third of its territory consists of water. Nowadays, Indonesian government concerns in Maritime's development, such as surface and underwater vessels. Those vehicles, generally, are used to protect illegal exploiting of its natural capital [2]. The moving object, particularly the surface marine vehicle, has six degrees of freedom: surging, swaying, yawing, rolling, pitching, and heaving [3]. Those movements are centered on three main axes. Some studies have presented mathematical modeling of ship maneuvering, especially in controlling the flow [4,5]. Ship control has been a popular theme in current research, mostly in control steering to get optimal performance $[1,6]$ purposing to design a trajectory tracking of the ship while maneuvering on the sea. Further ship problems were investigated by an adaptive control such as adaptive control design with extending Z-filter using error estimator for ship's path [7] and adaptive fuzzy robust control for ship steering autopilot [8]. Simultaneously, Nomoto's Model was also controlled using control steering in Nomoto's Model to get the autopilot design of the time-varying system[9].

Commonly mathematical modeling of ship maneuvering is very complicated. It has significant inertia, non-linearity, parameter perturbations, and random external disturbances such as wave, wind, and ocean current, uncertainty in course control. In detail, the mathematical modeling in this research forms nonlinear differential equations by considering four degrees of freedom: surging, swaying, yawing, and rolling with hydrodynamics derivatives factors [3][10]. It is assumed that pitching and heaving do not influence ship maneuvers. Interestingly, it is the most comprehend and covers the fundamental characteristic of a dynamic system. The problem of ship maneuvering is mostly about controlling the system with a nonlinear equation, especially in the auto-pilot system. It should be controlled by an appropriate method that can suit the unstable condition. Various advanced control methods are applied to solve the problems: Model Predictive Control (MPC), Disturbance Compensating Model Predictive Control (DC-MPC), Adaptive robust control, backstepping approach, and genetic algorithm $[7,9,11,12,13,14]$. However, some factors influencing the maneuvering should be calculated selected controller, degree of freedom, and environmental disturbances.

Control theory, interestingly, is improving along the time and comes with advanced methods followed by its application in diverse fields. One popular method, Pontryagin's Minimum Principle, is used to minimize nonlinear dynamical systems $[15,16]$ and advancement with stochastic MPC to control energy consumption [17]. In 2019, research about sliding mode control can provide a stability control system and fast dynamic response [18] and combine stochastic predictive control and max-plus algebra [19]. Simultaneously, a practical MPC enhances the performance of induction motor drive [20], the framework for modeling and representation of hybrid Model predictive control [21]. Those various predictive control applications allow this method to enforce in such ship heading control with its complexity. Furthermore, in 2019 Ueno et.al studied model ship control and estimation through the propeller and Haseltalab \&Negenborn determined control maneuvring and energy using MPC [22,23].

On the other hand, the environmental disturbance is one of the factors that could influence ship motion control. Waves, winds, and currents are the main types of natural disorders. Commonly, many kinds of research are not considering natural disturbances that will form a more complex structure of ship maneuvering. However, this research found ocean waves created by the wind on which has significant interaction while shipping maneuvers. Many control methods are used to control ship performance, especially against disturbance such as Model predictive control for a ship heading control [24,25,26,27]. This paper considered ocean waves formed by the wind on which has significant interaction while maneuvering. The wave itself can be approached by sinusoidal [28].

Motivated by these issues, this paper proposes the Disturbance Compensating Model Predictive Control (DC-MPC) method, the development of Model Predictive Control (MPC), in the crewless vehicle's application. The MPC itself is a strategy on designing control to gain a signal input by minimizing an objective function [20], while DC-MPC is advanced design system controls for handling disturbance directly based on feedback control. There are several main steps to control using this method. Firstly, the disturbance, in this case, is the wave, should be defined. Secondly, the system can be optimized and form disturbance compensating, distinguished between ordinary Model Predictive Control (MPC). Finally, it is used as an input in MPC's algorithm. DC-MPC purposed to fix disturbance that should be considered in a system properly [29]. 
This research develops ship motion control, which moved on the sea surface with high-speed maneuvering. This problem is solved using Disturbance Compensating Model Predictive Control. This research aims to give an alternative method that may be better than previous ones, particularly in controlling marine surface vehicles by calculating natural disturbance. It also can be used as fundamental for conducting advanced research in ship control design.

\section{RESEARCH METHOD}

This research aims a sophisticated control in surface marine vehicle by formulating a dynamical modeling of the maneuvering considering surge, sway, yaw, and roll. In this part, we present the algorithm of DC-MPC and apply into derived model.

\subsection{Mathematical Modelling}

The Surface marine vehicle is a moving object in which the performance can be represented by using Newton's law. Several papers have been proposed the mathematics model of ship maneuvering [2], in which ship maneuvering was generally represented by six DOF rigid-body equation of motion:

$$
M \dot{v}+C v=\tau
$$

where $v=[u, v, w, p, q, r]^{T}$ is hull's velocity and $\tau=[X, Y, Z, M, N]^{T}$ is external force and moment.

While this research is used Ship container as a model in this research to get the exact parameter and coefficients, Another approach to formulate modeling by using system identifying [30]. The formulation of dynamical modeling considers four degrees of freedom: surge, sway, yaw, and roll and forms nonlinear differential equation that should be linearized for getting a new system which is simpler and more natural to be analyzed and simulated.

The angle definition of ship maneuvering in this condition can be illustrated as in Figure 1.

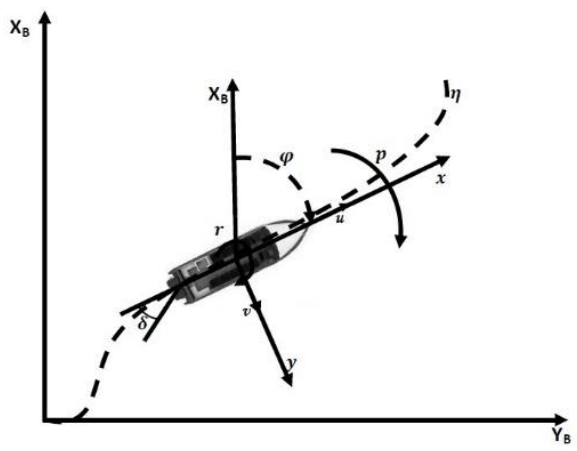

Figure 1. Definition of angle and position of motion

Based on Figure 1, the mathematical model of ship maneuvering in yaw, surge, roll, and sway can also be described as

$$
\left.\begin{array}{c}
\dot{x}=(u \cos \psi-v \sin \psi \cos \phi) \\
\dot{y}=(u \sin \psi+v \cos \psi \cos \phi) \\
\dot{\psi}=r \cos \phi \\
\dot{\phi}=p
\end{array}\right\}
$$

where $u, v, r, p$ denote surge, sway, yaw and roll velocity respectively. Variable $x, y, \psi, \phi$ are the surge displacement, sway displacement, yaw angle, and roll angle in the earth fixed frame. 
Equation (3) can be rewritten into a differential equation describing the rate of the surge, sway, yaw, and roll respect to time (s). In mathematics the formulation follows

$$
\left.\begin{array}{c}
\dot{u}=\frac{X^{\prime}+b v^{\prime} r v}{a} \\
\dot{v}=\frac{1}{b}\left(Y^{\prime}+d \dot{p}^{\prime}-c \dot{r}^{\prime}-a u^{\prime} r^{\prime}\right) \\
\dot{p}=\frac{K^{\prime}-W^{\prime} G M^{\prime} \phi+d \dot{v}^{\prime}+f u^{\prime} r^{\prime}}{e} \\
\dot{r}=\frac{N^{\prime}-x_{G}^{\prime} Y^{\prime}-c \dot{v}^{\prime}}{g}
\end{array}\right\}
$$

Where $\dot{u}, \dot{v}$ are surge and sway velocities respectively, while $\dot{r}, \dot{p}$ are yaw and roll angular velocities with $a=m^{\prime}+m_{x}^{\prime}, b=m^{\prime}+m_{y}^{\prime}, c=m_{y}^{\prime} \alpha_{y}^{\prime}, d=m_{y}^{\prime} I_{y}^{\prime}, e=I_{x}^{\prime}+J_{x}^{\prime}, f=m_{x}^{\prime} I_{x}^{\prime}, g=I_{z}^{\prime}+J_{z}^{\prime}$ meanwhile, $X^{\prime}, Y^{\prime}, K^{\prime}, N^{\prime}$ denotes hydrodynamic force and moment of ship: the normal rudder force, $F_{N}$, can be defined by:

$$
F_{N}=-\left(\frac{6.13 \Delta}{\Delta+2.25}+\frac{A R}{L^{2}}\right)\left(U_{R}^{2}+V_{R}^{2}\right) \sin \left(\alpha_{R}\right)
$$

where $A R$ is a rudder area, $\Delta$ is a ratio of the rudder, $U_{R}$ is rudder longitudinal, and $V_{R}$ is rudder lateral. The Equation (3) and (4) are mathematics models of ship motion system that should be controled and should be linearized before applying DC-MPC using the expansion of Jacobian matrix around stabilization points $\left(u_{0}, v_{0}, r_{0}, p_{0}, \delta_{0}, \psi_{0}, \phi_{0}\right)$. The initial velocity of the surge influences resultant ship manuvering:

Table 1. Description of the variable and parameter of the model

\begin{tabular}{cl}
\hline Variable & Interpretation \\
\hline$m^{\prime}$ & Mass \\
\hline$m_{x}^{\prime}$ & Added mass in the x-direction \\
\hline$m_{y}^{\prime}$ & Added mass in the y-direction \\
\hline$I_{x}^{\prime}$ & moment of inertia in the x-direction \\
\hline$I_{y}^{\prime}$ & moment of inertia in the y-direction \\
\hline$J_{x}^{\prime}$ & Added inertia moment in the x-direction \\
\hline$J_{y}^{\prime}$ & Added inertia moment in the y-direction \\
\hline$N_{v}$ & Coefficient of Hydrodynamic differential moment along z axes respect to $v$ \\
\hline$N_{r}$ & Coefficient of Hydrodynamic differential moment along z axes respect to $r$ \\
\hline$N_{\phi}$ & Coefficient of Hydrodynamic differential moment along z axes respect to $\phi$ \\
\hline$N_{p}$ & Coefficient of Hydrodynamic differential moment along z axes respect to $p$ \\
\hline$Y_{v}$ & Coefficient of Hydrodynamic differential force along y-axes respect to $v$ \\
\hline$Y_{r}$ & Coefficient of Hydrodynamic differential force along y-axes respect to $r$ \\
\hline$Y_{\phi}$ & Coefficient of Hydrodynamic differential force along y-axes respect to $\phi$ \\
\hline$Y_{p}$ & Coefficient of Hydrodynamic differential force along y-axes respect to $p$ \\
\hline$K_{v}$ & Coefficient of Hydrodynamic differential moment along with y-axes respect to $v$ \\
\hline$K_{r}$ & Coefficient of Hydrodynamic differential moment along with y-axes respect to $r$ \\
\hline$K_{\phi}$ & Coefficient of Hydrodynamic differential moment along with y-axes respect to $\phi$ \\
\hline$K_{p}$ & Coefficient of Hydrodynamic differential moment along with y-axes respect to $p$ \\
\hline$x_{G}$ & gravity \\
\hline
\end{tabular}

without being influenced by other velocities such as yaw and sways while stable

$$
U=\sqrt{u^{2}+v^{2}}=\sqrt{\left(u_{0}+\Delta u\right)^{2}+\Delta v^{2}}
$$

Ship maneuvering is stable when it constantly moves toward reference that have defined. There is no change both for surge velocity and sway velocity, so the stability point for surge velocity can be chosen, $u_{0}=$ 
15 knot, and sway velocity $v=0$. Consequently, other stable points are defined by $r_{0}=0, p_{0}=0, \phi_{0}=$ $0, \psi_{0}=0$, and the rudder angle is $\delta_{0}=0$.

State variables should be redefined as $u=x_{1}, v=x_{2}, r=x_{3}, p=x_{4}, \phi=x_{5}, \psi=x_{6}$, and $\delta=u$ for the rudder angle.

\subsection{Method}

The difference between MPC and DC-MPC is in their ability to process disturbance. While DC-MPC allows to minimize disturbance and create compensating to the plant, the MPC added the disturbance directly in state space. This paper focuses on the linear DC-MPC so that the very first step is linearizing Equation (2) and (4) using the Taylor series at initial values that have been defined.

The DC-MPC proposes a computationally, efficient two-step algorithm to handle disturbance by exploring the disturbance information [17]. The algorithm of DC-MPC follows several steps:

\section{Step 1}

Estimate the disturbance $\widehat{w}(k-1)$ of the previous time step $k-1$

The disturbance at time $\operatorname{step}(k-1), \widehat{w}(k-1)$ can be estimated follow:

$$
\widehat{w}(k-1)=x(k)-A x(k-1)-B \boldsymbol{u}(k-1)
$$

with the assumption, the disturbance at time step $k, w(k)$ can be estimated by

$$
w(k)=\widehat{w}(k-1)+\epsilon
$$

\section{Step 2}

The influence of disturbance is modeled as a first-order sea wave. Calculate the disturbance compensating control det $u$ by solving the optimization problem

$$
P_{\{\operatorname{det}\}}(\widehat{w}(k-1))=\min \|C B \operatorname{det} \boldsymbol{u}+C \widehat{w}(k-1)\|
$$

Subject to

$$
\begin{gathered}
C B \operatorname{det} u \leq-C \widehat{w}(k-1)-E \\
S \operatorname{det} \boldsymbol{u} \leq T
\end{gathered}
$$

Where $E=\max (C E)$, which $\in$ is the difference between wave $k$ and estimation wave $k-1$. The optimization output is the optimal disturbance compensating $\Delta u^{*}$ and it will be used as a factor that influences the boundary constraint of control input $k$ in MPC.

\section{Step 3}

Solve the optimization problem $P\left(x(k), \operatorname{det} \boldsymbol{u}^{*}\right)$ as follows

$$
P\left(x(k), \Delta \boldsymbol{u}^{*}\right)=\min \_\boldsymbol{u}(. \mid k) \sum_{j=1}^{N p}\left[x(k+j \mid k)^{T}\right] Q x(k+j \mid k)+u(k+j-1 \mid k)^{T} R u(k+j-1 \mid k)
$$

Constrains

$$
\begin{gathered}
x(k \mid k) \\
x(k+j+1 \mid k)=A x(k+j \mid k)+B u(k+j \mid k) \\
C x(k+j+1 \mid k) \leq D \\
S u(k \mid k) \leq T-S \Delta u^{*} \\
S u(k+j \mid k) \leq T-S \Delta u^{*}
\end{gathered}
$$

This step is an optimization algorithm that used Quadratic Programming, where $x(k), u(k), w(k)$ are vector of state, control input, and disturbance. Here $Q=Q^{T}$ dimension of matrix $\mathrm{Q}$ depends on the number of state $(n \times n)$. Then $R=R^{T}$ dimension of matrix $\mathrm{R}$ depends of the number of control input $(m \times n) . \mathrm{Q}$ and $\mathrm{R}$ are parameters under assume [16] 


$$
\left[\begin{array}{ll}
Q & 0 \\
0 & R
\end{array}\right] \leq 0
$$

\section{Step 4}

Implementation of the following control system:

$$
u(k)=u^{*}(k \mid k)+\Delta u^{*}
$$

It means that $u(k)=u^{*}(k \mid k)+\Delta u^{*}$ is control optimal in this process.

The further process completes the model's mathematical analysis into computational using some coefficients and parameters of container ships shown in [3]. The simulation aims to get the best performance of maneuver in various Horizon Prediction.

\section{RESULT AND DISCUSSION}

Several steps of the analyzed method should be completed by the simulation to prove the hypotheses regarding DC-MPC. Simulation of ship maneuvering has been investigated using the nonlinear model and prediction of the empiric method [31,32]. The given initial values in simulation are $\bar{x}(0)=[u, v, r, p, \phi, \psi]=$ $\left[5,15 \frac{\mathrm{m}}{\mathrm{s}} ; 0 ; 0,0001 \frac{\mathrm{rad}}{\mathrm{s}} ; 0 ; 0\right]$ and $u(0)=0$, while horizon value $N_{p}$ is randomly chosen in 25 times simulation. The purpose of the DC-MPC method controls the stability of ship motion. Therefore the angular velocities of yaw, roll, and rudder angle should be limited into boundary constraints. The heading control angle velocity is close to $0^{\circ}$ unless there is disturbance such as sea wave.

The case is assumed that ship maneuvering has 10 knots of surge velocity. Meanwhile, reference of heading angle is calculated toward earth fixed axis $\left(X_{e}\right)$, ship motion is controlled for maneuvering parallel to axis- $x$, or on the other words heading angle reach $0^{\circ}$. It is continued by controlling ship motion to move forward, which has 10 knots for surge velocity.

It is interesting to note that variation of prediction horizon values $N_{p}$ can influence the heading ship's position. Consequently, the simulation involves many kinds of prediction horizon to know how big it will affect the ship maneuvering when other parameters are fixed. The validation of the mathematical analysis in design control of the system applies in different Horizon prediction $\left(N_{p}\right)$ using a random integer from 1 until 100. However, this paper shows some comparisons of those result $N_{p}=40,60$, and 80 . Those three conditions performed differently showed by Fig. 2, 3, and 4.

To further validate its performance, the DC-MPC scheme is evaluated and compared with M-MPC, which the disturbances do not before estimate.

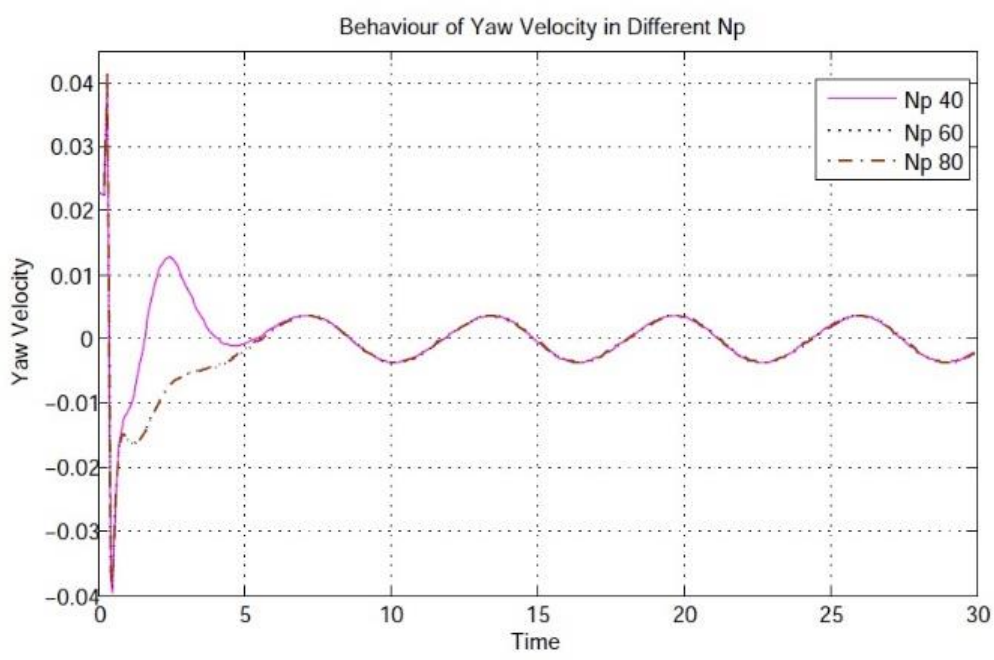

Figure 2. Yaw Velocity's behavior with Variation of $N_{p}$ 
Furthermore, Figure 2 illustrates connectivity between angle velocity of yaw and the time for prediction horizon variation: $N_{p}=40,60$, and 80 . The yaw velocity closes into the reference number in $4.9^{\text {th }}$ time when $N_{p}=60$. In comparison, it approaches the reference number in around $5^{t h}$ for $N_{p}=40$, which takes a bit more time than $N_{p}=60$. Moreover, these three yaw velocities for varying horizon predictions have similar movement after $5.1^{\text {th }}$ time until the end of the simulation.

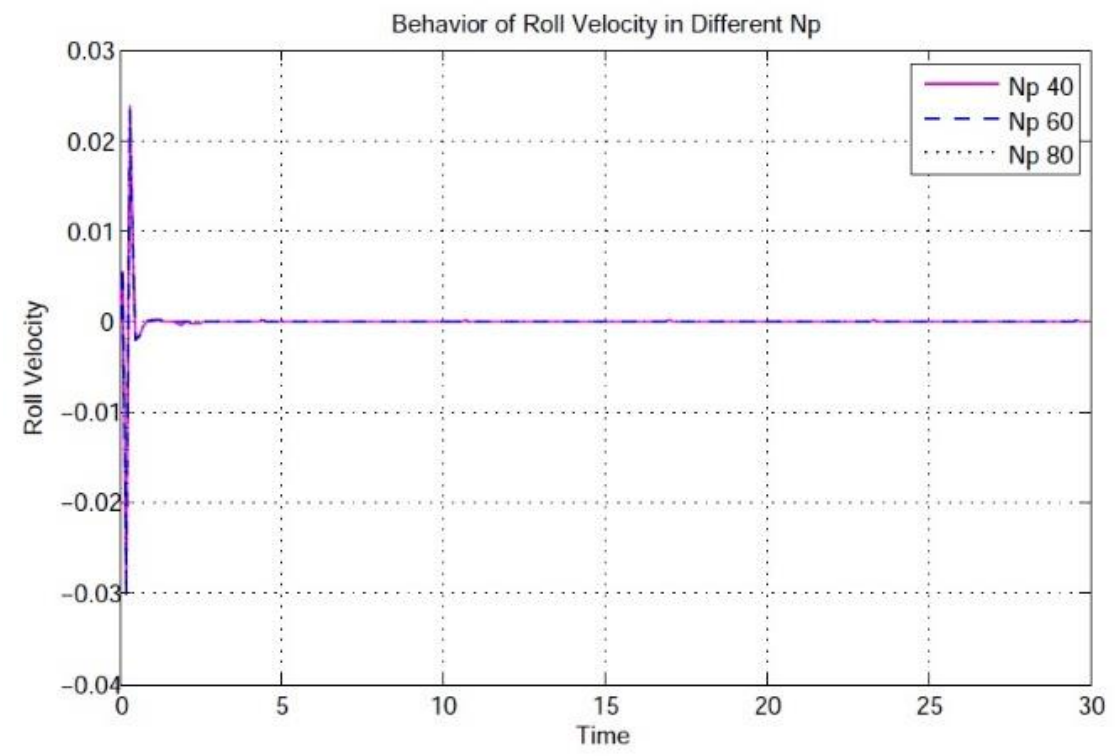

Figure 3. Roll Velocity's Behavior with Variation of $N_{p}$

Similarly, Figure 3 shows the behavior of roll velocity for difference prediction horizon in which $N_{p}=$ 60 reaches the reference at $1.6^{\text {th }}$ time. Meanwhile, the $N_{p}=40$ needs the time to be stable after handling the disturbance wisely in $1.2^{\text {th }}$. Besides, roll velocity can be well-controlled within the already given constraint, which isp $\leq 0.0106 \mathrm{rad} / \mathrm{s}$.

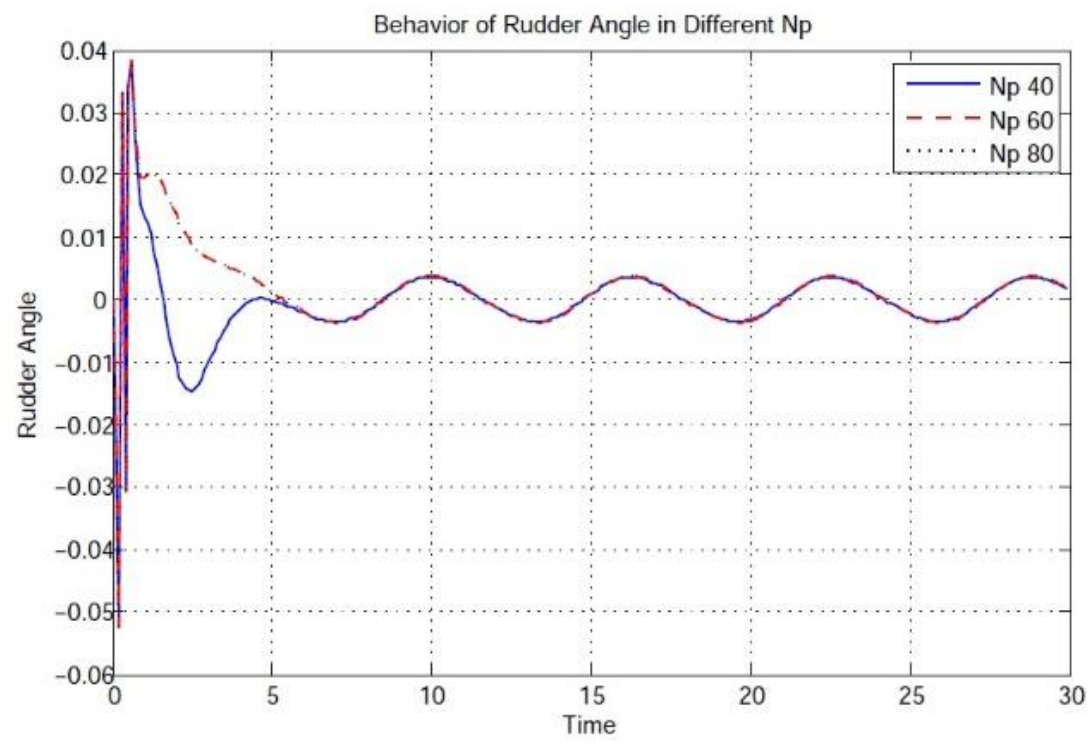

Figure 4. Rudder Angle's Behavior with Variation of $N_{p}$

Furthermore, Figure 4 compares the rudder angle with the variation of prediction horizon values: 40 , 60 , and 80 . It can be seen that those three prediction horizons move within the constraint $(0.175 \mathrm{rad} / \mathrm{s})$, whereas prediction horizons below 25 perform passing the constraint. Conversely, the heading angle behavior for prediction horizon, $N_{p} 40$ and 60 , can reach the reference (nearly zero) before 5 units of time, which were at 4.8 and 3.8 , respectively.

It is noticeable that the behavior of the rudder angle, yaw, and roll velocity remains stable. 


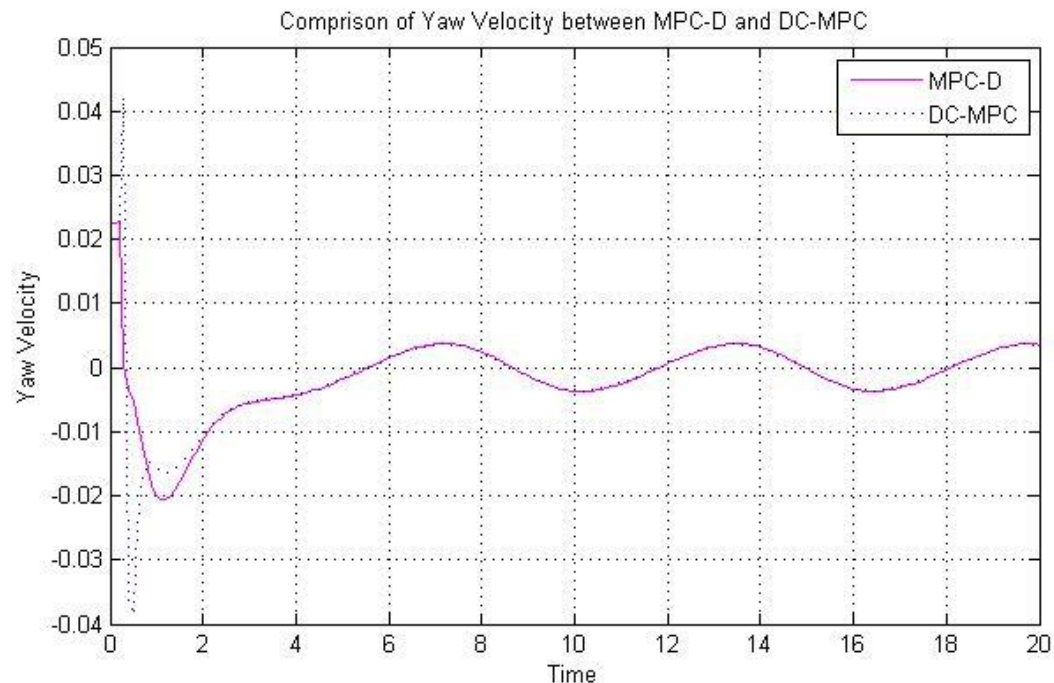

Figure 5. Comparison of Yaw Velocity using MPC and DC-MPC

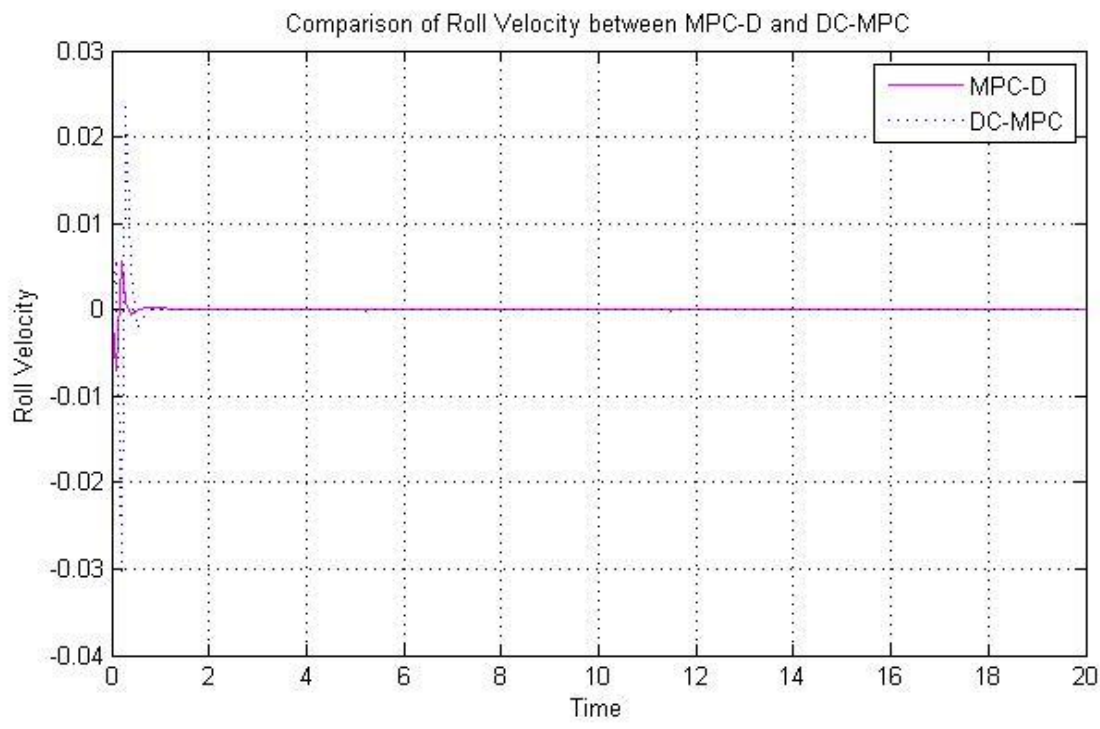

Figure 6. Comparison of Roll Velocity using MPC and DC-MPC

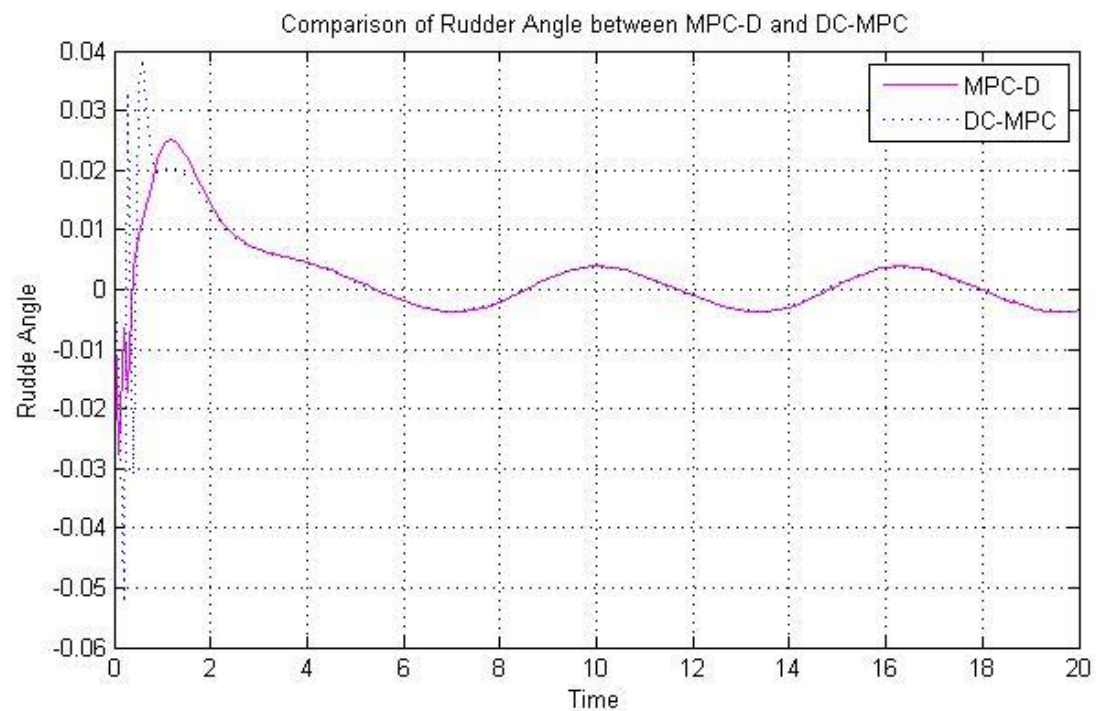

Figure 7. Comparison of Rudder Angle using MPC and DC-MPC 
The simulation in Figures 5-7 compares the DC-MPC method and MPC with the Disturbance (MPC-D) method with $N_{p}=60$. The Figures 5-7 show that the states and control input has closely behaved and moved around the reference for both methods. Besides, both methods are working very well under the given constraints. However, as shown in Figures 6 and 7, the performance of roll velocity and rudder angle using DC-MPC reaches the references relative faster than MPC, which are in $1.8^{\text {th }}$ and $2^{\text {nd }}$ times.

\section{CONCLUSION}

In this paper, the mathematical modeling of sea surface vehicle considering four degrees of freedoms, namely surging, swaying, yawing, and rolling forming nonlinear differential equations is proposed. The formulation consists of ten state variables and one control input. Based on the discussion mentioned above, we conclude some interesting points:

a. The first order waves that influence each axis ordinate of the moving object (ship) will be used as environmental disturbances.

b. The DC-MPC controller system analysis showed that it works well for the ship heading control with disturbance.

c. The DC-MPC method is used since it can control the ship's maneuvering while considering the ocean waves.

d. The simulation result of container ship shows that ship maneuvering's stability depends on the number of prediction horizons in which closed to $\mathrm{Np}=60$, so the optimum stabilization was gained. It means that this method can minimize error, and the disturbance compensating could control the environment disturbance that had given.

e. Comparing the controlling of ship maneuvring using DC-MPC and MPC with disturbance (MPC-D) showed that DC-MPC is better than MPC.

\section{REFERENCES}

[1] R. Fraga and L. Sheng, An Effective State-Space Feedback Autopilot for Ship Motion Control, vol. 2, No. 2, , page 62-69, 2012.

[2] Developer, M. BPPT “Kembangkan Kapal Selam Mini”. Media Indonesia., https://mediaindonesia.com/read/detail/120093bppt-kembangkan-kapal-selam-mini. [accessed August 30, 2017].

[3] T. I. Fossen, Guidance and Control of Ocean Vehicles (John Wiley and Son, 1999).

[4] Z. Yu and J. Amdahl, Full six degrees of freedom coupled dynamic simulation of ship collision and grounding, Marine Structures, vol. 47, pp 1-22, May 2016.

DOI: doi.org/10.1016/j.marstruc.2016.03.001

[5] R. L. Levin and L. Larsson, Sailing yacht performance prediction based on coupled CFD and rigid body 6 degrees of freedom, Ocean Engineering, vol. 144, pp. 362-373, November, 2017.

DOI: doi.org/10.1016/j.oceaneng.2017.09.052

[6] E. W. McGookin, D. J. Murray-Smith, Y. Li, and T. I. Fossen, Ship steering control system optimisation algorithms, Control Engineering Practice, vol. 8, no. 4, pp 429-443, 2000.

[7] J. Wu, H. Peng, K. Ohtsu, G. Kitagawa, and T. Itoh, Ship's tracking control based on nonlinear time, Applied Ocean Research, vol. 36, pp 1-11, June 2012.

DOI: doi.org/10.1016/j.apor.2012.01.004

[8] J. Velagic, Z. Vukic, and E. Omerdic, Adaptive fuzzy ship autopilot for track-keeping, IFAC Proceedings Volumes, Volume 33, Issue 21, pp 129-134, August 2000.

DOI: doi.org/10.1016/S1474-6670(17)37063-5

[9] J. Du, C. Guo, S. Yu and Y. Zhao, Adaptive Autopilot Design of Time-Varying Uncertain Ships With Completely Unknown Control Coefficient, IEEE Journal of Oceanic Engineering, vol. 32, no. 2, pp 346-352, April 2007,

DOI 10.1109/JOE.2007.893684.

[10] Y. Wang and S. Boyd, Fast Model Predictive Control Using Online Optimization. IEEE Transaction on Control Systems Technology, Vol. 18, No. 2, pp 267-278, March 2010.

[11] A. Witkowska, M. Tomera, and R. Smierzchalski, A Backstepping approach to ship course control, Int. J. Appl. Math. Comput. Sci., Vol. 17, No. 1, pp 73-85, 2007. 
[12] H. P. Guo \& Z. J. Zou, System-based investigation on 4-DOF ship maneuvering with hydrodynamic derivatives determined by RANS simulation of captive model tests. Applied Ocean Research, Volume 68, pp 11-25, 2017.

DOI: doi.org/10.1016/j.apor.2017.08.006

[13] Z. Li, J. Sun and S. Oh, Path following for marine surface vessels with rudder and roll constraints: An MPC approach, 2009 American Control Conference, pp 3611-3616, June 2009.

DOI: 10.1109/ACC.2009.5160302.

[14] Purnawan, Heri \& Asfihani, Tahiyatul \& Adzkiya, Dieky \& Subchan, Disturbance compensating model predictive control for warship heading control in missile firing mission. Journal of Physics: Conference Series, vol. 1108, pp. 1-6, 2018

DOI: 10.1088/1742-6596/1108/1/012035

[15] S.S. Tabatabaei, M. J., Yazdanpanah, and M.S., Tavazoei, Formulation and numerical solution for fractional order time optimal control problem using pontryagin's minimum principle, IFAC-Papers Online, Vol. 50, Issue 1, pp 9224-9229, July 2017. DOI: https://doi.org/10.1016/j.ifacol.2017.08.1280

[16] S. Cahyaningtias and S. Subchan, Application of Pontryagin's minimum principle in optimum time of missile manoeuvring, Cauchy Journal, vol. 4, no. 3, pp 107-111, November 2016.

DOI: https://doi.org/10.18860/ca.v4i3.3534

[17] S. Xie, X. Hu, Z. Xin and J. Brighton, Pontryagin's minimum principle based model predictive control of energy management for a plug-in hybrid electric bus, Applied Energy, Vol. 236, pp 893-905, February 2019.

DOI: https://doi.org/10.1016/j.apenergy.2018.12.032

[18] S. Khongkhachat and S. Khomfoi, A sliding mode control strategy for a grid-supporting and grid-forming power converter in autonomous AC microgrids, International Review of Electrical Engineering, Vol. 14, No. 2, pp 118, April 2019.

DOI: https://doi.org/10.15866/iree.v14i2.16331.

[19] M. A. Mossa and A. A. Z. Diab, Effective model predictive control approach for faulty induction motor drive, International Review of Electrical Engineering, Vol. 14, No. 5, pp 314-327, September 2019.

DOI: https://doi.org/10.15866/iree.v14i4.16837

[20] J. Qu, Z. Zhang, and H. Zhang, An improved predictive control model for stochastic max-plus-linear systems, Chaos, Solitons, and Fractal, Vol. 128, pp 210-218, November 2019.

DOI: https://doi.org/10.1016/j.chaos.2019.07.009

[21] P. Karelovic, E. Putz and A. Cipriano, A framework for hybrid model predictive control in mineral processing, Control Engineering Practice, Vol. 40, pp: 1-12, July 2015.

DOI: https://doi.org/10.1016/j.conengprac.2015.02.006

[22] M. Ueno, R. Suzuki, \& Y. Tsukada, Model Ship Control and Estimation of Full-scale Propeller Torque in Wind and Waves, IFAC-PapersOnLine, Volume 51, Issue 29, pp 201-206, 2018.

https://doi.org/10.1016/j.ifacol.2018.09.493.

[23] Ali Haseltalab, Rudy R. Negenborn, Model predictive maneuvering control and energy management for all-electric autonomous ships, Applied Energy, Volume 251, pp 1-27, 2019, https://doi.org/10.1016/j.apenergy.2019.113308.

[24] F. Zhou, C. Wang, F. Li, J. Ruan, and W. Pan, Nonlinear Active Disturbance Rejection Controller Resarch for Ship Course Tracking, Chinese Control and Descision Conference IEEE, vol. 08, pp 4856-4861, 2008.

DOI: $10.1109 / C C D C .2008 .4598251$

[25] D. K. Rahma Putri, Subchan, D. Adzkiya and T. Asfihani, "Ship Heading Control for Dubins Path Tracking and Collision Avoidance using Model Predictive Control," 2019 International Conference on Information and Communications Technology (ICOIACT), Yogyakarta, Indonesia, 2019, pp. 628-633,

doi: 10.1109/ICOIACT46704.2019.8938455.

[26] E. F. Camacho and C. Bordons, Model Predictive Control. Great Britain: Springer-Verlag London, 1999.

[27] Subchan, G. A. Aulia, T. Asfihani and D. Adzkiya, "Ship Heading Control Of Warship Using Disturbance Compensating Model Predictive Control Method," 2018 International Seminar on Research of Information Technology and Intelligent Systems (ISRITI), Yogyakarta, Indonesia, 2018, pp. 571-576,

doi: 10.1109/ISRITI.2018.8864480.

[28] Z. Li and J. Sun, Disturbance compensating model predictive control with application to ship heading control, IEEE Transactions on control systems technology, vol. 20, no. 1, pp 257-265, 2012.

DOI: 10.1109/TCST.2011.2106212

[29] Z. Li\& J. Sun \& R. Beck, Evaluation and Modification of a Robust Path Following Controller for Marine Surface Vessels in Wave Fields. Journal of Ship Research. Vol. 54. No.2 pp 141-147, 2010. 
[30] Luo, W. and Li, X., Measures to diminish the parameter drift in the modeling of ship manoeuvring using system identification, Applied Ocean Research, Vol. 67, pp 9-20, September 2017.

https://doi.org/10.1016/j.apor.2017.06.008

[31] P. Du, A. Quahsine, K.T. Toan, and P. Sergent, Simulation of ship maneuvering in a confined waterway using a nonlinear model based on optimization techniques, Ocean Engineering, vol. 142, pp 194-203, September 2017.

DOI: https://doi.org/10.1016/j.oceaneng.2017.07.013

[32] S. Sutulo and C.G. Soares, On the application of empiric methods for prediction of ship manoeuvring properties and associated uncertainties, Ocean Engineering, Vol. 186, August 2019.

DOI: https://doi.org/10.1016/j.oceaneng.2019.106111 
